\title{
Vitamin D Levels in Young Adult Cataract Patients: A Case-Control Study
}

\author{
Çağlar Öktem Fatih Aslan
}

Department of Ophthalmology, Alaaddin Keykubat University Alanya Education and Research Hospital, Antalya, Turkey

\section{Keywords}

Cataract $\cdot$ Vitamin D deficiency $\cdot$ Young adult

\begin{abstract}
Objective: We aimed to investigate whether a relationship is present between early cataract formation and vitamin $D$ in young adults. Methods: A total of 37 cataract patients (18 males and 19 females) and 53 healthy participants ( 27 males and 26 females) under the age of 60 years were included in this study. The $25-\mathrm{OH}$ vitamin D values were measured in all subjects and the mean vitamin D levels compared between the 2 groups. Additionally, the differences between the vitamin D levels of the genders in both groups were investigated. Results: The mean age of the study group was $48.1 \pm$ 8.5 (range 33-59) years, and the mean age of the control group was $49.3 \pm 7.8$ (range $31-59$ ) years $(p=0.48$ and $p=$ 0.83 ). The mean vitamin D level was $15.6 \pm 8.4 \mathrm{ng} / \mathrm{mL}$ in the study group and $20.8 \pm 7.1 \mathrm{ng} / \mathrm{mL}$ in the healthy subjects ( $p=0.002$ ). Among the females, the vitamin $D$ level was $10.6 \pm 4.7 \mathrm{ng} / \mathrm{mL}$ in the study group and $18.1 \pm 6.4 \mathrm{ng} / \mathrm{mL}$ in the control group ( $p=0.0001)$. No significant difference was found between the groups among the males ( $p=0.24)$. Conclusion: We found vitamin $D$ deficiency to be associated with early age-related cataract in a statistically significant manner. We believe it is worth investigating the reason for this concurrence with large longitudinal studies.
\end{abstract}

(c) 2020 S. Karger AG, Basel

\section{Introduction}

Cataract is the loss of transparency of the lens inside the eye. It is the most common cause of visual loss and blindness worldwide [1]. It can be seen at any age but is generally encountered at advanced ages. The rate of visually significant cataract decreasing visual acuity to below the $20 / 40$ level has been reported to be $2.5 \%$ at the age of 40-49 years, $6.8 \%$ at $50-59$ years, $20 \%$ at $60-69$ years, $42.8 \%$ at $70-79$ years, and $68.3 \%$ in those aged over 80 years [2]. Cataracts are usually accompanied by an underlying disease when they develop in young subjects. For example, the risk of cataract has been reported to increase 2-5 times in diabetes [3]. This risk may increase to 15-25 times in diabetic patients under the age of 40 years [4]. Other diseases associated with early cataract development include myotonic dystrophy, atopic dermatitis, neurofibromatosis, hypoparathyroidism, and Down syndrome [2]. Various ocular conditions such as uveitis, high myopia, retinitis pigmentosa, and blunt and penetrating ocular trauma in addition to steroid use are also among the causes of early cataract formation [2].

Vitamin D is a steroid prohormone found in the circulation. It is present in 2 forms as D3 and D2. A significant part of the D3 form is synthesized in the skin with the help of the sun's rays, while the D2 form is ingested from foods of plant origin [5-7]. Vitamin D is one of the antioxidant vitamins and is known to decrease oxidative

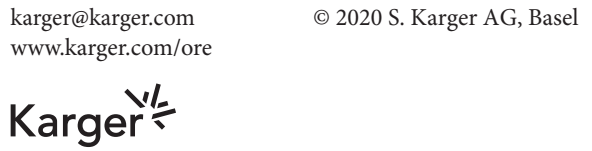


stress $[8,9]$. It regulates the expression of the antioxidant genes that prevent this oxidative stress [10]. It therefore plays a role in the pathogenesis of various ocular diseases such as diabetic retinopathy and glaucoma [11-15]. Vitamin $\mathrm{D}$ also has anti-inflammatory features. It prevents excessive stimulation of cytotoxic T cells. It inhibits the release of pro-inflammatory cytokines and increases the release of anti-inflammatory cytokines $[5,6]$.

Vitamin D deficiency is a global health problem mainly due to insufficient exposure to sunlight. A total of 1 billion people worldwide are estimated to have vitamin $\mathrm{D}$ deficiency or insufficiency [16]. A 25-hydroxy vitamin D level in the circulation of $\geq 30 \mathrm{ng} / \mathrm{mL}$ is considered to be normal, while $21-29 \mathrm{ng} / \mathrm{mL}$ is defined as vitamin D insufficiency and values under $20 \mathrm{ng} / \mathrm{mL}$ are defined as vitamin D deficiency [5].

In recent years, the number of studies investigating the relationship between vitamin D deficiency and systemic and ocular diseases has increased. Based on the fact that oxidative stress and inflammation are important factors in cataract formation, various studies have evaluated the relationship between vitamin $\mathrm{D}$ and cataract [17-23]. These studies had focused on the relationship between senile cataract and vitamin $\mathrm{D}$. In our study, we aimed to investigate the relationship between cataract formation and vitamin $\mathrm{D}$ in young adults who were primarily of Turkish-Caucasian ethnic origin.

\section{Materials and Methods}

A total of 37 adult patients (18 males and 19 females) who were diagnosed with cataract at the Alaaddin Keykubat University Training and Research Hospital's Department of Ophthalmology between March and September 2019 and a total of 53 healthy participants of similar age and gender were included in this study. All cases were Caucasians who were living in Mediterranean climate. This sectional case-control study was conducted in accordance with the Helsinki Declaration principles and approval was obtained from the Clinical Studies Ethics Committee of the Alaaddin Keykubat University (approved on June 27, 2019; Research No. 10354421). All participants were informed of the study and they provided written consent. After recording the systemic and ophthalmologic history, a detailed ophthalmologic examination that included best-corrected visual acuity measurement with the Snellen scale, anterior segment examination with a biomicroscope, intraocular pressure measurement with a pneumatic tonometer, and a dilated fundus examination was performed. We then collected 2 $\mathrm{mL}$ of venous blood from the forearm of each participant and the plasma 25-hydroxy vitamin D levels were measured at the Biochemistry Laboratory with the immunoassay (ARCHITECT 25$\mathrm{OH}$ vitamin D assay, Abbott Diagnostics) method.

Vitamin D Levels in Young Adult

Cataract Patients
Table 1. Demographic characteristics of cataract patients and healthy control subjects

\begin{tabular}{lccc}
\hline & Study group & Control group & $p$ value \\
\hline Age, mean \pm SD, years & $48.1 \pm 8.5$ & $49.3 \pm 7.8$ & 0.48 \\
Male, $n(\%)$ & $18(48)$ & $27(51)$ & 0.83 \\
Female, $n(\%)$ & $19(52)$ & $26(49)$ & \\
\hline
\end{tabular}

$p$ values $<0.05$ are statistically significant.

\section{Inclusion Criteria}

Adult patients younger than the age of 60 years who were diagnosed with cortical, nuclear, or subcapsular cataract were included in the study as the study group. Voluntary subjects of the same age whose eye examination was completely normal and who had no risk factors for cataract formation or vitamin D deficiency were included as the control group.

\section{Exclusion Criteria}

Patients with a history of complicated ocular or systemic cataract, glaucoma, high myopia, retinitis pigmentosa, uveitis, history of previous ocular surgery or ocular trauma, alcohol abuse, diabetes, tobacco use, myotonic dystrophy, atopic dermatitis, neurofibromatosis, hypoparathyroidism, Down syndrome, osteoporosis, autoimmune skin disease, or skin cancer; patients who used calcium supplements, or osteoporosis drugs; and those with current or past use of topical, systemic, or inhaled steroids were excluded.

\section{Statistical Analysis}

Categorical variables were expressed as frequency and percentage values. Continuous variables were presented as mean, standard deviation, median, minimum, and maximum values. The ShapiroWilk test was used to determine whether the continuous variables were normally distributed. Correlations between categorical variables were evaluated using Pearson's $\chi^{2}$ analysis. For independent variables, intergroup comparisons were done using the MannWhitney U test. Spearman correlation analysis was used to detect correlations between the variables. A $p$ value $<0.05$ was considered statistically significant. Analyses were done using the NCSS 11 (Number Cruncher Statistical System) 2017 Statistical Software and the MedCalc Statistical Software, version 18 (MedCalc Software bvba, Ostend, Belgium; http://www.medcalc.org; 2018).

\section{Results}

We found 55 cataract patients under the age of 60 years during the study. We excluded 14 patients from the study due to systemic reasons ( 10 patients due to diabetes, 1 patient due to atopy, 1 patient due to calcium replacement treatment, and 2 patients due to systemic steroid use) and 4 were excluded due to ophthalmologic reasons ( $2 \mathrm{pa}-$ tients due to traumatic cataract, 1 patient due to glauco$\mathrm{ma}$, and 1 patient due to chronic uveitis). The mean age 


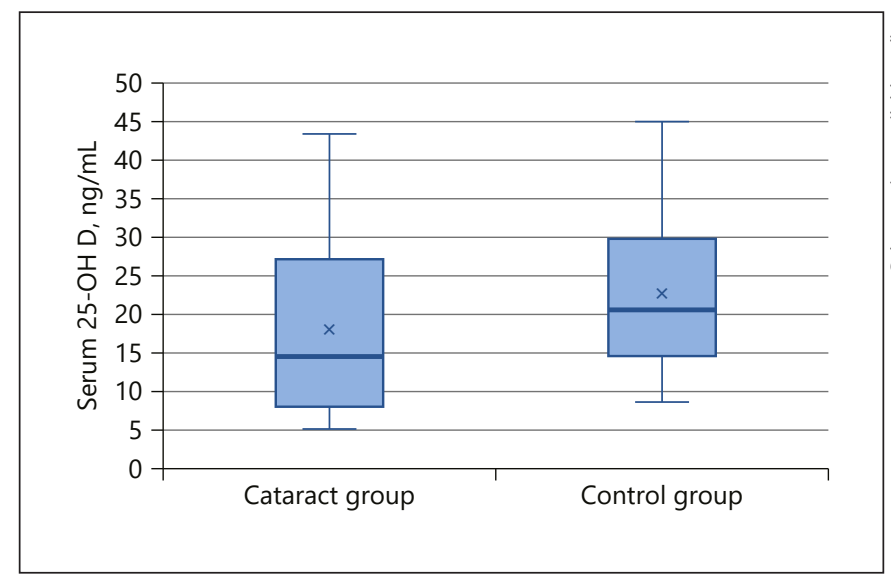

Fig. 1. The mean vitamin $\mathrm{D}$ levels in cataract patients and healthy subjects

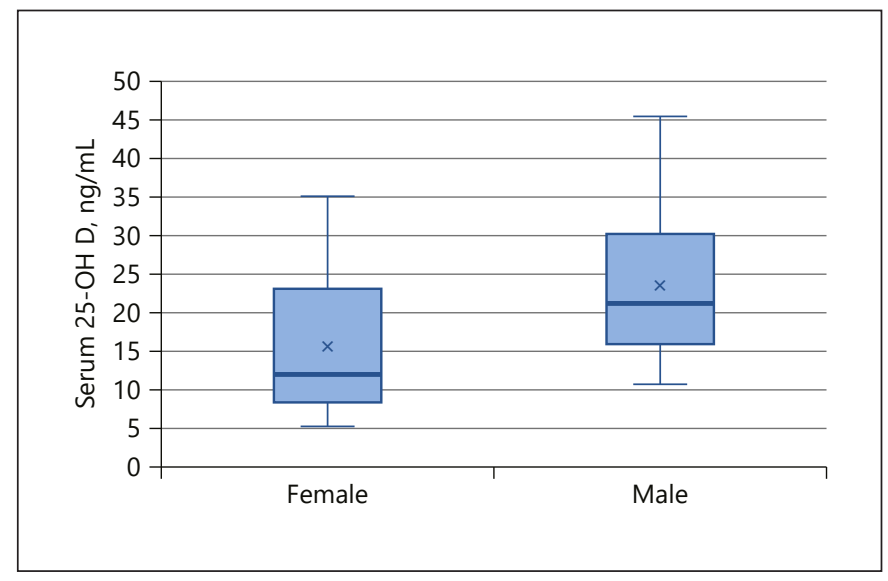

Fig. 2. The mean vitamin $D$ levels in female cataract patients and male cataract patients

of the 37 remaining cataract patients (18 males and 19 females) included in the study was $48.1 \pm 8.5$ (range 3359 ) years, and the mean age of the 53 individuals ( 27 males and 26 females) in the control group was $49.3 \pm 7.8$ (range 31-59) years. There was no difference between the groups in terms of age and gender $(p=0.48$ and $p=0.83)$ (Table 1).

The mean visual acuity was $0.74 \pm 0.36$ (raange 1.40.3 ) with the LogMAR chart in the study group. Most of the cataracts were not hard. We found grade 2-3 nuclear cataract in 15 cases, mixed cataract in 13 cases, and posterior subcapsular cataract (PSC) in 9 cases.

The vitamin D level was found to be significantly lower in the PSC and nuclear cataract types than in the control group ( $p=0.047$ and $p=0.002$, respectively). No sig-
Table 2. Comparison of vitamin D in cataract patients and healthy control subjects

\begin{tabular}{llll}
\hline Vitamin D level & $\begin{array}{l}\text { Patients, } \\
\text { mean } \pm \text { SD }\end{array}$ & $\begin{array}{l}\text { Controls, } \\
\text { mean } \pm \text { SD }\end{array}$ & $p$ value \\
\hline All subjects & $15.6 \pm 8.4$ & $20.8 \pm 7.1$ & $\mathbf{0 . 0 0 2 *}$ \\
Males & $20.9 \pm 8.3$ & $23.6 \pm 6.8$ & 0.24 \\
Females & $10.6 \pm 4.7$ & $18.1 \pm 6.4$ & $\mathbf{0 . 0 0 0 1 *}$ \\
\hline \multirow{2}{*}{$*$ values $<0.05$ are statistically significant. } \\
\hline
\end{tabular}

nificant difference was found in mixed type cataracts $(p=$ 0.178). Comparison of the vitamin D levels in anterior subcapsular cataract $(11.81 \mathrm{ng} / \mathrm{mL})$, nuclear cataract (13.68 ng/mL), and mixed cataract patients (14.96 ng/ $\mathrm{mL}$ ) showed no statistically significant difference between the groups ( $p=0.743$ ).

The mean vitamin $\mathrm{D}$ level was $15.6 \pm 8.4 \mathrm{ng} / \mathrm{mL}$ in cataract patients and $20.8 \pm 7.1 \mathrm{ng} / \mathrm{mL}$ in healthy subjects ( $p=0.002)$ (shown in Fig. 1). The mean vitamin D level was $10.6 \pm 4.7 \mathrm{ng} / \mathrm{mL}$ in female cataract patients and 20.9 $\pm 8.3 \mathrm{ng} / \mathrm{mL}$ in male cataract patients $(p=0.0001)$ (shown in Fig. 2). The mean vitamin $D$ level in females was 10.6 $\pm 4.7 \mathrm{ng} / \mathrm{mL}$ in the study group and $18.1 \pm 6.4 \mathrm{ng} / \mathrm{mL}$ in the control group $(p=0.0001)$ (Table 2 ).

\section{Discussion}

Vitamin $\mathrm{D}$ is an antioxidant vitamin and is known to decrease oxidative stress $[8-10,19]$. It also has anti-inflammatory features and plays a role in resisting chronic inflammation. Vitamin D prevents excessive stimulation of cytotoxic T cells, inhibits the release of pro-inflammatory cytokines, and increases the release of anti-inflammatory cytokines $[5,6]$. Oxidative stress is an important factor for cataract formation. Certain antioxidant vitamins are known to decrease the risk of cataract in animal models and humans $[18,19,24]$. Cataracts in infants can be seen in some metabolic disorders and also in rickets due to vitamin D deficiency [25]. Although it is known that vitamin $\mathrm{D}$ deficiency is associated with cataract in infants, there are only a few studies on the concurrence of cataract that appear without any etiology in adults and vitamin $\mathrm{D}$ deficiency. The role of vitamin $\mathrm{D}$ in advanced age senile cataract patients has been investigated in these studies [19-23]. We evaluated whether there was a relationship between cataracts seen in young adults and vitamin D levels in this study. 
Although cataracts are usually seen at advanced ages, they can develop at any age. The cataract rate is $68.3 \%$ in subjects over the age of 80 years but only $2.5 \%$ under the age of 50 years, the mean age of our patients [2].

We found vitamin D levels to be significantly lower in young adult cataract patients than in healthy subjects in a similar age-group. A circulating 25-hydoxy vitamin D level below $20 \mathrm{ng} / \mathrm{mL}$ is defined as vitamin D deficiency [5]. Based on this information, we found that vitamin $\mathrm{D}$ deficiency was present in our cataract patients. This deficiency was more evident in our female patients.

Abdellah et al. [22] studied patients aged 50 years and over with nuclear, cortical, and subcapsular cataract. The vitamin D level was lower than in the healthy control subjects in cataract patients and especially in those with a nuclear cataract. The authors interpreted this result as indicating a possible role of $25-\mathrm{OH}$ vitamin $\mathrm{D}$ deficiency in age-related cataract [22]. Vitamin D deficiency was also found to be associated with a PSC in another study on relevant risk factors. An increase in vitamin D intake was reported to decrease the PSC incidence [20]. The cataract risk was reported to decrease with high serum vitamin D levels in a study conducted on Korean subjects by Jee and Kim [19]. It was emphasized that increasing the vitamin D level, for example, by taking vitamin $\mathrm{D}$ supplements, could be useful in preventing cataract development [19]. Park and Choi found the serum $25-\mathrm{OH}$ vitamin $\mathrm{D}$ level to be inversely proportional to the risk of nuclear cataract in their study where they investigated the relationship between serum 25$\mathrm{OH}$ vitamin $\mathrm{D}$ and age-related cataract. Being exposed to sufficient sunlight was reported to help prevent cataract formation. According to Park and Choi, these findings could suggest the clinical use of vitamin $\mathrm{D}$ in the prevention of age-related cataracts and especially nuclear cataracts [21].

The results of our study were similar to previous studies. We found vitamin D levels in cataract patients to be significantly lower than that in healthy subjects. We also found vitamin $\mathrm{D}$ levels in females to be lower than that in males. This may be explained by the fact that men are exposed to more sunlight as a result of their outdoor activities. Vitamin D was also found to be lower in female patients in the study of Abdellah et al. [22].

Considering the antioxidant effects of vitamin $\mathrm{D}$ in decreasing oxidative stress, it is possible that the vitamin is of critical importance in diseases where oxidative stress is involved in the pathogenesis [5]. In fact, UV light exposure is an independent risk factor for the development of cataract because it leads to photooxidation of lens proteins. Vitamin D, on the other hand, is mainly produced directly on the skin secondary to UV exposure and may have a preventive effect on cataract development due to its positive effect on the photooxidation of proteins $[19,26]$. Whether vitamin D supplementation will be useful in preventing cataract progression is currently not fully proven and this effect has not been sufficiently explained [26]. However, identifying a modifiable risk factor for cataract development would be of great value. According to the report of Abdellah et al. [22], delaying cataract development is important and appropriate when the costs are considered and especially in developing countries [22]. We agree with this approach.

Calcium is closely related to vitamin $\mathrm{D}$, and studies on experimental animal models have reported that calcium could show anti-cataract activity in steroid-mediated cataracts with its antioxidant effect [27]. Paradoxically, it has also been stated that calcium could start cataract development by inducing cortical opacities following protease induction in lens epithelial cells $[28,29]$. The membrane-bound steroid-binding protein in the lens epithelial cells that plays a role in Ca mobilization is also thought to have an effect on steroid-induced cataract development [30]. The role of vitamin D in these calcium-associated processes is not fully clear.

One of the limitations of our study was that other inflammatory mediators were not studied together with vitamin $\mathrm{D}$. We realized this shortcoming toward the end of our study. Evaluating the vitamin D level and inflammatory mediators together in the future may provide more useful results. Another point that could be considered a limitation is that we did not query the sunlight exposure duration in our patients. It is possible that the patients with cataract stayed indoors longer or were exposed to sunlight less. We did not query this factor as our patients and healthy control subjects constituted 2 healthy groups that lived in the same region with the same climate and had similar lifestyles.

In conclusion, we found vitamin $\mathrm{D}$ deficiency to be associated with early age-related cataract in a statistically significant manner. Although it was not possible to evaluate causality, we believe it is worth investigating the reason for this concurrence with large longitudinal studies. We therefore think our study will guide future studies on the subject in addition to contributing to the current literature. 


\section{Statement of Ethics}

This sectional case-control study was conducted in accordance with the Helsinki Declaration principles, and approval was obtained from the Clinical Studies Ethics Committee of the Alaaddin Keykubat University (approved on June 27, 2019; Research No. 10354421). All participants were informed of the study, and they provided written consent.

\section{Conflict of Interest Statement}

The authors have no conflicts of interest to declare.

\section{Funding Sources}

The authors did not receive any funding.

\section{Author Contributions}

C.O. conceived the original idea. C.O. and F.A. collected the data and C.O. wrote the manuscript. Both authors discussed the results and contributed to the manuscript.

\section{References}

1 Asbell PA, Dualan I, Mindel J, Brocks D, Ahmad M, Epstein S. Age-related cataract. Lancet. 2005;365(9459):599-609.

2 Thompson J, Lakhani N. Cataracts. Prim Care. 2015;42(3):409-23.

3 Klein BE, Klein R, Wang Q, Moss SE. Olderonset diabetes and lens opacities. The beaver dam eye study. Ophthalmic Epidemiol. 1995; 2(1):49-55.

4 Bernth-Peterson P, Bach E. Epidemiologic aspects of cataract surgery. Frequencies of diabetes and glaucoma in a cataract population. Acta Ophthalmol. 1983;61:406-16.

5 Dal NE, Islekel H. Vitamin D as an immunomodulatory and antioxidant molecule: association between vitamin $D$ deficiency and systemic sclerosis. Turk J Immunol. 2019;7(1): 57-68.

6 Gil Á, Plaza-Diaz J, Mesa MD. Vitamin D: classic and novel actions. Ann Nutr Metab. 2018;72(2):87-95.

7 Uitterlinden AG, Fang Y, Van Meurs JB, Pols HA, Van Leeuwen JP. Genetics and biology of vitamin D receptor polymorphisms. Gene. 2004;338(2):143-56.

8 Alvarez JA, Chowdhury R, Jones DP, Martin GS, Brigham KL, Binongo JN, et al. Vitamin $\mathrm{D}$ status is independently associated with plasma glutathione and cysteine thiol/disulphide redox status in adults. Clin Endocrinol. 2014;81(3):458-66.

9 Mangge H, Weghuber D, Prassl R, Haara A, Schnedl W, Postolache TT, et al. The role of vitamin $\mathrm{D}$ in atherosclerosis inflammation revisited: more a bystander than a player? Curr Vasc Pharmacol. 2015;13(3):392-8.

10 Berridge MJ. Vitamin D cell signalling in health and disease. Biochem Biophys Res Commun. 2015;460(1):53-71.

11 Millen AE, Voland R, Sondel SA, Parekh N, Horst RL, Wallace RB, et al. Vitamin D status and early age-related macular degeneration in postmenopausal women. Arch Ophthalmol. 2011;129(4):481-9.

12 Parekh N, Chappell RJ, Millen AE, Albert DM, Mares JA. Association between vitamin $\mathrm{D}$ and age-related macular degeneration in the third national health and nutrition examination survey, 1988 through 1994. Arch Ophthalmol. 2007;125(5):661-9.

13 Payne JF, Ray R, Watson DG, Delille C, Rimler E, Cleveland J, et al. Vitamin D insufficiency in diabetic retinopathy. Endocr Pract. 2012;18(2):185-93.

14 Patrick PA, Visintainer PF, Shi Q, Weiss IA, Brand DA. Vitamin D and retinopathy in adults with diabetes mellitus. Arch Ophthalmol. 2012;130(6):756-60.

15 Yoo TK, Oh E, Hong S. Is vitamin D status associated with open-angle glaucoma? A cross-sectional study from South Korea. Public Health Nutr. 2014;17(4):833-43.

16 Holick MF. Vitamin D deficiency. N Engl J Med. 2007;357(3):266-81

17 Berthoud VM, Beyer EC. Oxidative stress, lens gap junctions, and cataracts. Antioxid Redox Signal. 2009;11(2):339-53.

18 Mosad SM, Ghanem AA, El-Fallal HM, ElKannishy AM, El Baiomy AA, Al-Diasty AM, et al. Lens cadmium, lead, and serum vitamins $\mathrm{C}, \mathrm{E}$, and beta carotene in cataractous smoking patients. Curr Eye Res. 2010;35(1):23-30.

19 Jee D, Kim EC. Association between serum 25-hydroxyvitamin D levels and age-related cataracts. J Cataract Refract Surg. 2015;41(8): 1705-15.

20 Brown CJ, Akaichi F. Vitamin D deficiency and posterior subcapsular cataract. Clin Ophthalmol. 2015 Jun 16;9:1093-8.

21 Park S, Choi NK. Serum 25-hydroxyvitamin $\mathrm{D}$ and age-related cataract. Ophthalmic Epidemiol. 2017;24(5):281-6.
22 Abdellah MM, Mohamed Mostafa E, Salama $\mathrm{EH}$, Roshdy Mohamed E. Association of serum 25-hydroxyl vitamin $\mathrm{D}$ deficiency and age-related cataract: a case-control study. J Ophthalmol. 2019;15:9312929.

23 Rao P, Millen AE, Meyers KJ, Liu Z, Voland $\mathrm{R}$, Sondel $\mathrm{S}$, et al. The relationship between serum 25-hydroxyvitamin D levels and nuclear cataract in the Carotenoid Age-Related Eye Study (CAREDS), an ancillary study of the women's health initiative. Invest Ophthalmol Vis Sci. 2015;56(8):4221-30.

24 Zheng Selin J, Rautiainen S, Lindblad BE, Morgenstern R, Wolk A. High-dose supplements of vitamins $\mathrm{C}$ and $\mathrm{E}$, low-dose multivitamins, and the risk of age-related cataract: a population-based prospective cohort study of men. Am J Epidemiol. 2013;177(6):54855.

25 Endres W, Shin YS. Cataract and metabolic disease. J Inherit Metab Dis. 1990;13(4):50916.

26 Sella R, Afshari NA. Nutritional effect on agerelated cataract formation and progression. Curr Opin Ophthalmol. 2019;30(1):63-9.

27 Velpandian T, Nirmal J, Gupta P, Vijayakumar AR, Ghose S. Evaluation of calcium dobesilate for its anti-cataract potential in experimental animal models. Methods Find Exp Clin Pharmacol. 2010;32(3):171-9.

28 Gupta PD, Johar K, Vasavada A. Causative and preventive action of calcium in cataractogenesis. Acta Pharmacol Sin. 2004 Oct;25(10): $1250-6$.

29 Duncan G, Wormstone IM. Calcium cell signalling and cataract: role of the endoplasmic reticulum. Eye. 1999 Jun;13(Pt 3b):480-3.

30 Zhu XL, Sexton PS, Cenedella RJ. Characterization of membrane steroid binding protein mRNA and protein in lens epithelial cells. Exp Eye Res. 2001 Aug;73(2):213-9. 